\title{
The Role of High-Density Lipoproteins in Reducing the Risk of Vascular Diseases, Neurogenerative Disorders, and Cancer
}

\author{
Donovan McGrowder, ${ }^{1}$ Cliff Riley, ${ }^{2}$ Errol Y. St. A. Morrison, ${ }^{3}$ and Lorenzo Gordon ${ }^{4}$ \\ ${ }^{1}$ Department of Pathology, Faculty of Medical Sciences, University of the West Indies, Mona Campus, Kingston 7, Jamaica \\ ${ }^{2}$ College of Health Sciences, University of Technology, 237 Old Hope Road, Kingston 6, Jamaica \\ ${ }^{3}$ Principal's Office, University of Technology, 237 Old Hope Road, Kingston 6, Jamaica \\ ${ }^{4}$ Department of Medicine, Faculty of Medical Sciences, University of the West Indies, Kingston 7, Jamaica \\ Correspondence should be addressed to Donovan McGrowder, dmcgrowd@yahoo.com
}

Received 4 September 2010; Accepted 4 November 2010

Academic Editor: Gerhard M. Kostner

Copyright ( $) 2011$ Donovan McGrowder et al. This is an open access article distributed under the Creative Commons Attribution License, which permits unrestricted use, distribution, and reproduction in any medium, provided the original work is properly cited.

\begin{abstract}
High-density lipoprotein (HDL) is one of the major carriers of cholesterol in the blood. It attracts particular attention because, in contrast with other lipoproteins, as many physiological functions of HDL influence the cardiovascular system in favourable ways unless HDL is modified pathologically. The functions of HDL that have recently attracted attention include anti-inflammatory and anti-oxidant activities. High anti-oxidant and anti-inflammatory activities of HDL are associated with protection from cardiovascular disease. Atheroprotective activities, as well as a functional deficiency of HDL, ultimately depend on the protein and lipid composition of HDL. Further, numerous epidemiological studies have shown a protective association between HDLcholesterol and cognitive impairment. Oxidative stress, including lipid peroxidation, has been shown to be the mediator of the pathologic effects of numerous risk factors of Alzheimer's disease. Lifestyle interventions proven to increase HDL- cholesterol levels including "healthy" diet, regular exercise, weight control, and smoking cessation have also been shown to provide neuro-protective effects. This review will focus on current knowledge of the beneficial effects of HDL-cholesterol as it relates to cardiovascular diseases, breast and lung cancers, non-Hodgkin's lymphoma, as well as its neuroprotective potential in reducing the risk of Alzheimer's disease and dementia.
\end{abstract}

\section{Introduction}

1.1. Composition of HDL. Plasma high-density lipoproteins (HDLs) are small, dense, and spherical lipid-protein complexes and are normally considered to consist of those plasma lipoprotein particles which fall into the density range of $1.063-1.210 \mathrm{~g} / \mathrm{mL}$. HDL particles are composed of an outer layer containing free cholesterol, phospholipid, and various apolipoproteins (Apo), which covers a hydrophobic core consisting primarily of triglycerides and cholesterol esters [1]. The major proteins are Apo A-I (Mr 28,000) and Apo AII (Mr 17,000). Apo A-I, the primary protein constituent of these particles, accounts for about $60 \%$ of the protein content of HDL. Apo A-I is synthesized in the intestines and liver and is thought to be largely responsible for the antiatherogenic effects of HDL. Some HDL particles carry only Apo A-I, whereas others contain both Apo A-I and Apo A-II [2].
Other apolipoprotein species found in HDL particles include Apo A-IV, Apo C (C-I, C-II, and C-III), and Apo E. Several subtypes of HDL particles have been identified on the basis of density, electrophoretic mobility, particle size, and apolipoprotein composition [3]. Differences in particle size are mainly the result of the number of apolipoprotein particles and the volume of the cholesterol ester in the core of the particle [3].

$\mathrm{HDL}$ can be classified into larger, less dense $\mathrm{HDL}_{2}$ or smaller, denser $\mathrm{HDL}_{3}$ which falls within the density ranges $1.063-1.125$ and $1.125-1.210 \mathrm{~g} / \mathrm{mL}$, respectively. Although the major proportion of $\mathrm{HDL}$ is normally present in $\mathrm{HDL}_{3}$, individual variability in HDL levels in human populations usually reflects different amounts of $\mathrm{HDL}_{2}$ [4]. $\mathrm{HDL}_{2}$ is richer in particles containing Apo A-I without Apo A-II, whereas $\mathrm{HDL}_{3}$ is richer in particles containing both Apo A-I and Apo A-II [5]. 
HDL particles have multiple biological effects that could contribute to their antiatherothrombotic action including anti-inflammatory, antioxidant, and profibrinolytic activities [2]. The health benefits of HDL as documented in the literature are many. The purposes of this paper are to review current knowledge on the beneficial effects of HDLcholesterol as it relates to (i) cardiovascular diseases, (ii) breast and lung cancers as well as non-Hodgkin's lymphoma, and (iii) Alzehemier's disease and dementia.

\section{HDL-Cholesterol and Coronary Heart Disease}

2.1. Relationship between HDL-Cholesterol and Coronary Heart Disease. Numerous prospective cohort studies support a powerful inverse correlation between circulating HDL-cholesterol and coronary risk among patients with normal or elevated low-density lipoprotein- (LDL-) cholesterol $[6,7]$. Low HDL-cholesterol levels increase the risk of coronary heart disease (CHD) and analysis of the largest US epidemiologic studies including the Framingham Heart Study, the Lipid Research Clinics (LRC) Primary Prevention Trial, the LRC Prevalence Mortality Followup Study, and the Multiple Risk Factor Intervention Trial (MRFIT) substantiated that, on average, each one (1) $\mathrm{mg} / \mathrm{dL}$ increase in HDLcholesterol reduces CHD risk by $2 \%$ in men and 3\% decrease in women [8]. The Framingham Heart Study have supported the role of low HDL-cholesterol as an independent risk factor for coronary artery disease $(\mathrm{CAD})$ and demonstrated that subjects with the highest HDL-cholesterol levels exhibit the lowest risk of developing CAD. Further, based on 14 years of surveillance, the Framingham Study showed that there is an inverse relation between HDL-cholesterol and the incidence of CAD [9]. Subsequent follow-up revealed that study participants at the 80th percentile of HDL-cholesterol were found to have half the risk for developing CAD when compared with subjects at the 20th percentile of HDL-cholesterol [9]. Among patients aged 50 to 80 years without ischaemic heart disease (IHD), after a mean follow-up of 4 years, the risk of myocardial infarction (MI) or IHD death decreased by $25 \%$ for every $10 \mathrm{mg} / \mathrm{dL}$ increase in HDL-cholesterol [9].

The Israeli Ischemic Heart Disease Study examined the CHD and all-cause mortality of some 8000 Israeli men aged 42 years and older and found that subjects with low total cholesterol and high HDL-cholesterol had the lowest rates of CAD-associated morbidity and mortality [10]. The Physicians' Health Study showed that subjects with low HDL-cholesterol had increased risk for CAD. Both $\mathrm{HDL}$-cholesterol and $\mathrm{HDL}_{2}$ levels were associated with a substantially decreased risk of $\mathrm{MI}$, but the $\mathrm{HDL}_{3}$ level was the strongest predictor, the relative risk being 0.3 [11]. Levels of Apo A-I and Apo A-II were also associated with decreased risk [11]. The Prospective Cardiovascular Munster Study (PROCAM) demonstrated that subjects with HDLcholesterol levels $\leq 35 \mathrm{mg} / \mathrm{dL}$ were at 3 times greater risk for CAD compared with those who had HDL-cholesterol levels $\geq 35 \mathrm{mg} / \mathrm{dL}$ [12].
2.2. HDL-Cholesterol as a Therapeutic Target. Reductions in LDL-cholesterol using statins form the cornerstone of treatment of hyperlipidemia to reduce cardiovascular morbidity and mortality. Low serum concentrations of HDLcholesterol are one of the major risk factors for adverse events related to coronary atherosclerosis [8] and are highly prevalent among patients with acute coronary syndromes [13]. Niacin is the most effective therapy available for the treatment of low HDL-cholesterol, with a nonlinear dose-related increase in HDL-cholesterol of approximately $20 \%$ observed with modest drug doses (approximately $1 \mathrm{~g}$ per day) $[14,15]$. In the Collaborative Atorvastatin Study Group which involved a randomized trial of the effects of atorvastatin and niacin in patients with combined hyperlipidemia or isolated hypertriglyceridemia, atorvastatin increased HDL-cholesterol by $4 \%$ and niacin by $25 \%$ [16]. The specific mechanism of action of niacin is not well understood, but it appears to reduce Apo B secretion, thereby lowering both very low density lipoprotein (VLDL) and LDL, increasing Apo A-I, and lowering lipoprotein(a) [17]. The ARBITER (Arterial Biology for the Investigation of the Treatment Effects of Reducing Cholesterol-) 2 study examined the effects of niacin added to background statin therapy on HDL-cholesterol and carotid intima-media thickness (CIMT), a validated surrogate cardiovascular end point [18]. After 12 months of therapy, extended-release niacin increased HDL-cholesterol by $21 \%$ and decreased the rate of CIMT progression [18]. Therefore, the addition of extendedrelease niacin to statin therapy slowed the progression of atherosclerosis among individuals with known coronary heart disease and moderately low HDL-cholesterol [18].

In the Helsinki Heart Study and the Veterans Affairs High-Density Lipoprotein Cholesterol Intervention Trial (VA-HIT), treatment with gemfibrozil was associated with reduction in CVD events $[19,20]$. The Helsinki Heart Study examined the effect of gemfibrozil on lipid parameters and cardiovascular outcomes among high-risk middle-aged men without IHD and with primary dyslipidemia [19]. After 5 years of follow-up, treatment with gemfibrozil increased HDL-cholesterol by $11 \%$, decreased LDL-cholesterol and triglycerides by $11 \%$ and $35 \%$, respectively, and reduced the incidence of MI and IHD death by $34 \%$. The study demonstrated that for every one (1) $\mathrm{mg} / \mathrm{dL}$ increase in HDL-cholesterol, the CHD risk decreased by $2 \%$ to $3 \%$, independent of changes in LDL-cholesterol [19]. In the VAHIT cohort, gemfibrozil was associated with a significant $22 \%$ reduction in the risk of fatal and nonfatal $\mathrm{CHD}$, and it significantly reduced the relative risk of investigatordesignated stroke [20]. Some evidence indicates that the benefits seen in the VA-HIT cohort may be partly due to additional effects of fibrates on apolipoprotein synthesis and lipoprotein metabolism $[21,22]$. In contrast, the results of studies using other fibrates such as bezafibrate and fenofibrate have been negative. Bezafibrate has no effect on the incidence of $\mathrm{CHD}$ and of stroke combined but may reduce the incidence of nonfatal coronary events, particularly in those aged $<65$ years at entry, in whom all coronary events may also be reduced [23]. Fenofibrate did not significantly reduce the risk of the primary outcome of coronary events; 
however, it did reduce total cardiovascular events, mainly due to fewer non-fatal MIs and revascularisations [24].

2.3. Mechanism Involved in the Beneficial Effects of HDLCholesterol. The beneficial role of HDL-cholesterol in reducing atherosclerotic disease burden is complex and likely involves multiple mechanisms and biochemical pathways. The primary mechanism by which HDL-cholesterol is thought to reduce cardiovascular risk is reverse cholesterol transport, a pathway for removing free cholesterol from the macrophage in the arterial wall and returning it to the liver for excretion into bile [7, 25]. HDL-cholesterolmediated reductions in cardiovascular risk could occur through a variety of other pathways, including raising HDLcholesterol levels (by decreasing catabolism or increasing synthesis) and having a larger number of particles available with which to antagonize proatherogenic stimuli [26]. Collectively, HDL and its components [methionine resides in Apo A-I, paraoxonase 1 (PON1), platelet activating factor(PAF-) acetylhydrolase, and other antioxidant enzymes] can reduce oxidized lipid species in LDL particles, rendering them less atherogenic. This may help prevent atherosclerosis, acute coronary syndromes, and restenosis after coronary angioplasty [27].

HDLs have antioxidant activity through the antioxidative properties of Apo A-I, and the presence of enzymes such as PON1, glutathione-peroxidase, and PAF-acetylhydrolase. Paraoxonases 1 is an HDL-associated enzyme with antioxidant properties. There are data suggesting that the direct antioxidant effect of HDL on LDL oxidation, measured as a reduction in lipid peroxides, is likely mediated by PON1 [28]. Impaired PON1 activity was found to be closely linked to increased risk of cardiovascular mortality [29]. Moreover, PON1 activity is decreased in patients with type 2 diabetes with [30] or without CAD [31].

HDLs seem to exert a beneficial effect on endothelium function by modulating the activity and/or production of a number of molecules [such as nitric oxide (NO), prostacyclin $\left(\mathrm{PGI}_{2}\right)$, endothelin, and $\left.\mathrm{PAF}\right]$, and affecting vascular tone and thrombogenicity [32]. Plasma HDLcholesterol levels have been found to be an independent predictor of NO-dependent peripheral vasodilation in healthy individuals [33], hyperlipidaemic and diabetic patients [34, 35], and patients with CHD [36]. Further, HDLs display an antithrombotic effect by inhibiting platelets aggregation, reducing von Willebrand factor levels, and enhancing the activity of activated protein $\mathrm{C}$ and $\mathrm{S}$ [37].

\section{HDL-Cholesterol and Risk of Cancer}

3.1. HDL-Cholesterol and Breast Cancer Risk. Boyd and McGuire in 1990 proposed that women with high levels of HDL-cholesterol may have an increased risk of breast cancer [38]. This hypothesis by these authors based on the observation that many known and suspected breast cancer risk factors are associated with increased levels of HDLcholesterol, and experimental studies that suggest that HDLcholesterol has a role in the proliferation of breast tumor cells in vitro $[39,40]$. Further, HDL-cholesterol could play a role in carcinogenesis through its influence on cell cycle entry, via a mitogen-activated protein kinase-dependent pathway [41] or regulation of apoptosis [42]. Therefore, in vitro studies that show that HDL-cholesterol promotes the growth of breast cancer cell lines in tissue culture suggest that a direct, causal effect is biologically plausible $[40,43]$. However, it is unknown if a similar effect on tumor cells occurs in vivo.

Two studies have addressed prospectively the association of HDL-cholesterol and breast cancer incidence $[44,45]$. Hoyer and Engholm investigated the association between serum lipids and breast cancer risk in a cohort of 5,207 Danish women, who participated in The Glostrup Population Studies between 1964 and 1986 [44]. They found an inverse association between serum HDL-cholesterol and risk of breast cancer, with HDL-cholesterol being significantly lower among women who developed breast cancer during follow-up [44]. Gaard and colleagues in a prospective study examined the relationship between blood lipids and breast cancer risk in pre and postmenopausal Norwegian women. They found no association between breast cancer risk and blood lipids in the total population during 7 to 13 years of follow-up [45].

Several studies have reported lower levels of HDLcholesterol in breast cancer patients than in control subjects [46-49]. HDL-cholesterol levels were found to be significantly lower in pre- and postmenopausal women with benign and malignant breast disease [46]. Kokoglu et al. reported significant increase in triglycerides and VLDL-cholesterol and decrease in HDL- and LDL-cholesterol levels in patients with stage IV disease when compared to those with stage I breast cancer [47]. A decrease in HDL-cholesterol, especially in the $\mathrm{HDL}_{2}$ subfraction, was observed in newly diagnosed breast cancer patients. Besides, HDL particle from these patients showed increased Apo A-I/HDL-cholesterol ratio [47]. Further, there are several reports that have shown that tumor progression from localized to metastatic disease is associated with declining HDL-cholesterol levels [43, 47].

Two population-based screening surveys involving Norwegian women found that low HDL-cholesterol, as part of the metabolic syndrome, is associated with increased post-menopausal breast cancer risk, and HDL-cholesterol association was confined to women in the heavier subgroup with body mass index $(\mathrm{BMI}) \geq 25 \mathrm{~kg} / \mathrm{m}^{2}$ [50]. The risk of post-menopausal breast cancer among overweight and obese women in the highest serum HDL-cholesterol quartile was one-third the risk of women in the lowest serum HDLcholesterol quartile. According to the authors, these findings suggest an interaction between metabolic disturbances (i.e., overweight or obesity and low-serum HDL-cholesterol) in postmenopausal breast carcinogenesis [50]. In a nested casecontrol study by Moorman et al., there was a positive association between HDL-cholesterol in serum stored for more than 20 years and postmenopausal breast cancer risk. Further, an inverse association with premenopausal breast cancer risk was observed [51].

3.2. HDL-Cholesterol and Lung Cancer Risk. Cancer patients often present altered serum lipid profile including changes of HDL-cholesterol level. Case-control studies of newly 
diagnosed lung cancer have shown that HDL-cholesterol levels are reduced in lung cancer cases relative to levels observed in the control groups [52-55]. Siemianowicz et al. evaluated serum level of HDL-cholesterol in patients with squamous cell and small cell lung cancer and its dependence on histological type and clinical stage of lung cancer. They found that there were no statistically significant differences of HDL-cholesterol level between the histological types or between clinical stages of each histological type of lung cancer [52]. Decreased serum HDL-cholesterol was also reported in advanced nonresectable lung cancer patients [53]. Kucharska-Newton et al. examined prospectively the association of baseline plasma HDL-cholesterol levels with incidence of lung cancer in subject of the Atherosclerosis Risk in Communities (ARIC) cohort. They found relatively weak inverse association of HDL-cholesterol with lung cancer that was dependent on smoking status, even after exclusion of cases diagnosed within 5 years of baseline [56]. In the Alpha-Tocopherol, Beta-Carotene Cancer Prevention (ATBC) Study cohort, higher HDL-cholesterol levels were related to modestly decreased risk of cancer overall; this association remained after excluding cases diagnosed during the first 15 years of follow-up [57].

Biological mechanisms that might link low plasma levels of HDL-cholesterol with cancer are not well understood [38, 55]. The function of HDL-cholesterol in reverse cholesterol transport is important in development of atherosclerosis; however, it is not obvious how this function of HDLcholesterol could influence carcinogenesis [58]. Further, HDL regulation of cell cycle entry through a mitogen activated protein kinase-dependent pathway [41] and apoptosis [42], modulation of cytokine production, and antioxidative function [59] has been considered and is biologically plausible. The association between higher HDL-cholesterol and lower overall cancer incidence observed in the ATBC cohort is biologically plausible, as HDL- cholesterol has antiinflammatory properties [59]. However, it is also plausible that this association reflects the effect of factors that are associated with both HDL-cholesterol and risk of cancer, such as inflammation. Inflammation reduces HDL-cholesterol [60] and likely increases risk of lung cancer [61].

3.3. HDL and Lymphoma Risk. Lipoprotein abnormalities seen in patients with inflammatory diseases are thought to develop secondary to circulating cytokines and the accompanying acute-phase response. Lymphoma patients often exhibit abnormal lipid metabolism. Clinical studies of lymphoma patients have reported lipid abnormalities that are similar to the dyslipidemia observed in inflammatory and infectious diseases $[62,63]$. Further, a decrease in circulating HDL-cholesterol may occur during lymphomagenesis, reflecting underlying etiology such as inflammation.

Spiegel et al. investigated plasma lipids and lipoproteins at presentations in 25 patients with acute leukemia and nonHodgkin's lymphoma (NHL). They found that all patients demonstrated an abnormality in at least one plasma lipid fraction and most exhibited a predictable pattern of lipid alterations that consisted of extremely low levels of HDLcholesterol, elevated triglyceride, and elevated VLDL [62].
The degree of lipid abnormality was directly related to the underlying tumor burden and particularly to the presence of bone marrow involvement [62].

To evaluate the etiologic involvement of HDL-cholesterol in lymphomagenesis, Lim et al. investigated the association between prediagnostic serum HDL-cholesterol levels and the subsequent development of NHL during 17 years of follow-up of Finnish male smokers in the Alpha-Tocopherol Beta-Carotene (ATBC) Cancer Prevention Study cohort [64]. They observed an inverse association between HDLcholesterol and NHL, which changed with length of followup. High HDL-cholesterol was associated with lower risk of all NHLs during the first 10 years, but not with diagnoses during later follow-up [64]. Therefore, low circulating levels of HDL-cholesterol in lymphoma patients may occur before the clinical onset of cancer and may serve as a marker for inflammation-induced lymphomagenesis, rather than a consequence of lymphoma-induced acute-phase responses [63].

Studies have shown that chronic inflammation is known to reduce both serum HDL-cholesterol levels and its antiinflammatory properties $[65,66]$. Low HDL-cholesterol, therefore, may be a marker for the severity of systemic inflammation and inflammation-induced NHL risk. Conversely, high HDL-cholesterol itself may be protective against NHL. High-density lipoprotein-cholesterol seems to modulate inflammatory responses independent of nonHDL cholesterol levels [32] by suppressing chemotactic activity of monocytes and lymphocytes $[67,68]$ and inhibiting cytokine-induced expression of endothelial cell adhesion molecules. Further, HDL-cholesterol may protect the integrity of lymphocytes from oxidative damage $[25,69]$.

\section{HDL Protects the Aging Brain}

4.1. HDL, Alzheimer's Disease and Dementia. Over the past decade, abnormalities in brain lipid metabolism are increasingly recognized to be intimately related to the pathogenesis of such major neurodegenerative disorders as Alzheimer's disease (AD) and vascular dementia (VD). With respective frequencies of $70 \%$ and $15 \%$ of all dementias, $\mathrm{AD}$ and $\mathrm{VD}$ are the most common forms of dementia which are typically preceded by less dramatic cognitive decline, including decline in memory [70]. Both $\mathrm{AD}$ and atherosclerosis develop in parallel with the aging process and as such share a number of risk factors, including the presence of type 2 diabetes and elevated levels of total cholesterol and $\mathrm{Lp}(\mathrm{a})$ in midlife, thereby suggesting common pathophysiological pathways [71].

Cerebrovascular and Alzheimer's pathological changes frequently coincide in cases of dementia and may act synergistically in producing cognitive decline [72]. Lipoproteins such as HDL may influence neurodegeneration as a carrier of cholesterol. The extracellular deposition of amyloid beta $(\mathrm{A} \beta)$ in senile plaques constitutes one of the defining hallmarks of AD. There is evidence that brain cholesterol is related to amyloid metabolism in the brain and that disruption of cholesterol homeostasis in $\mathrm{AD}$ is linked to $\mathrm{A} \beta$ pathology [73]. Amyloid beta binds to HDL, maintaining 
its solubility in cerebrospinal fluid (CSF) and plasma. This HDL- $A \beta$ interaction prevents the deposition of $A \beta$ into the brain and can serve as a marker for neurodegenerative disease [74].

Oxidative stress, including lipid peroxidation, has been shown to be the mediator of the pathologic effects of numerous risk factors of $\mathrm{AD}$ [75]. Lifestyle interventions proven to increase HDL-cholesterol levels [76] including "healthy" diet, regular exercise, weight control, and smoking cessation have also been shown to provide neuroprotective effects [77, 78]. Moreover, elevated HDL-cholesterol levels potentially mediated by low cholesterol ester transfer protein (CETP) activity are also associated with longevity, improved cognition, and dementia-free survival [79]. Since HDL is the lipoprotein responsible for the efflux of cholesterol within cells of the brain, it may be that deficient levels or dysfunction of HDL-cholesterol may contribute to certain tauopathies or dysgenesis of synaptic processes, such that individuals with dyslipidemia may be more susceptible to neurodegenerative disease.

Singh-Manoux et al. in The Whitehall II Study examined the relationship between fasting serum lipids and shortterm verbal memory in middle-aged adults. They found that low HDL-cholesterol and decreasing levels over a 5-year follow-up period were associated with poor memory and decline in memory, respectively, [80]. Further, according to these authors, there are complex and variable biochemical mechanisms potentially linking HDL to AD. The different neuroprotective properties of HDL include accelerated maturation of synapses, maintenance of synaptic plasticity, improved metabolism of $\mathrm{A} \beta$, increase in hippocampal volume, and anti-inflammatory and antioxidative activities [80]. Further, brain HDL can suppress $\mathrm{A} \beta$ production by decreasing cellular cholesterol through the activation of reverse cholesterol transport mediated by $\mathrm{ABC}$ transporters [81]. HDL can directly bind excess $A \beta$ and thereby inhibit its oligomerisation [82]. Oligomerisation represents a major step in the transformation of the monomeric nontoxic peptide to the aggregated neurotoxic form that can account for memory impairment [83]. HDL may also remove $A \beta$ that accumulates in the vessel wall during the course of VD; by analogy with reverse cholesterol transport, such a process can be termed "reverse amyloid transport" [84]. In decreasing oxidative stress, HDL directly decreased $\mathrm{A} \beta$ production, as oxidative stress induces enhanced production of $A \beta$ as a potentially protective response [85]. Further, HDL can act on astrocytes to attenuate a local inflammatory reaction.

High-density lipoprotein particles traffic cholesterol in the brain and are related to cholesterol metabolism, which may play an important role in $\mathrm{A} \beta$ metabolism and deposition in the brain [86]. HDL-cholesterol is critical for the maturation of synapses and the maintenance of synaptic plasticity [87]. High-density lipoprotein-cholesterol has been found to be associated with hippocampal volume and dementia [88].

Next to $\mathrm{AD}, \mathrm{VD}$ is the second most common form of dementia in the elderly, yet few specific risk factors have been identified. Dementia occurs late in life, but it is increasingly recognized that there is a long preclinical phase characterized by progressive neuropathological changes that become clinically detectable later. The "life-long" view of dementia stresses the importance of vascular risk factors in midlife [89]. Different studies have investigated the relationship between lipid levels and the risk of VD. Many of them found an association with decreased levels of HDLcholesterol. Zuliani et al. found in a cross-sectional study that low HDL-cholesterol levels are associated with VD, but not with late-onset $\mathrm{AD}$ in a sample of 60 older subjects with VD compared with 54 controls [90]. Kuriyama et al. reported lower HDL-cholesterol levels in 44 patients with sporadic late-onset $\mathrm{AD}$ and 43 patients with VD compared with controls [91]. The Apo A-II level was disproportionally decreased in the patient groups. Further, the authors found that serum Apo A-II may involve the pathological process in the patients with senile dementia [91]. Muckle and Roy found significantly lower HDL-cholesterol levels in 5 men with multi-infarct dementia than in 12 men with senile dementia of the Alzheimer type [92].

In a population-based study involving 561 subjects 85 years old, Mini-Mental State Examination (MMSE) scores were significantly lower in subjects with low HDLcholesterol. Further, in a comparison of subjects with low HDL-cholesterol with subjects with high HDL- cholesterol, the odds ratio for dementia was 2.3. Thus, low HDLcholesterol is associated with cognitive impairment and dementia [93]. In the Northern Manhattan Stroke Study, Sacco et al. found that high HDL-cholesterol levels were related to a lower risk of stroke [94]. Increased HDLcholesterol levels were associated with reduced risk of ischemic stroke in the elderly and among different racial or ethnic groups. This supports HDL-cholesterol as an important modifiable stroke risk factor [94].

However, most longitudinal studies have failed to detect similar associations; HDL-cholesterol levels have not been associated with AD [95-97], vascular dementia [96, 97], or dementia [97]. Romas et al. found no association between HDL and either prevalent or incident $\mathrm{AD}$ [95]. In a prospective community-based cohort study of white, African American, and Caribbean Hispanic elderly, Reitz et al. found a weak relation between HDL-cholesterol levels and the risk of VD [96]. Further, in a population-based cohort study, there was no association between HDL-cholesterol in late life and subsequent risk of $\mathrm{AD}$ or dementia [97]. A possible explanation for the contradictory findings in the literature is that lipid levels tend to change as people become older [98]. This pattern can be partly explained by physiologic aging, unintentional or voluntary changes in lifestyle (due to increased public health awareness and initiation of interventional programs meant to lower cholesterol levels), selective mortality, or clinical-subclinical disease [99].

Another possible explanation for the conflicting epidemiologic associations between HDL-cholesterol and dementia is that other constituents of HDL-cholesterol such as Apo A-I may be more biologically relevant in $\mathrm{AD}$ or $\mathrm{VD}$ pathology and may therefore represent a more accurate dementia risk factor. In a case-control study of $45 \mathrm{AD}$ patients and 79 controls, levels of Apo A-I were lower in Japanese patients with late-onset nonfamilial AD [100]. The reductions in Apo A-I levels were observed in both 
carriers and noncarriers of the e4 allele [100]. Also, in a case-control study of $98 \mathrm{AD}$ patients and 59 elderly controls, serum Apo A-I levels were significantly lower in $\mathrm{AD}$ patients [101]. An Apo A-I cutoff value of $1.50 \mathrm{~g} / \mathrm{L}$ could distinguish between the two groups with a sensitivity of 71 percent and a specificity of 69 percent. Apo A-I levels were highly correlated with MMSE scores and were significantly and consistently lower in $\mathrm{AD}$ patients, independent of e4 status [101]. In a population sample of Japanese-American men, lower Apo A-I levels were associated with increased dementia risk more than a decade later. The associations seemed similar for $\mathrm{AD}$ and VD and were present over and above adjustments for HDL cholesterol and triglyceride levels [102].

\section{Conclusion}

It is clearly established that low HDL-cholesterol levels are a major independent risk factor for CVD. Further, large cohort studies have identified HDL-cholesterol as a strong, independent, and inverse predictor of risk of CHD. The recent advances in understanding the mechanisms by which HDL acts to reduce cholesterol content in vessel walls have suggested a number of therapeutic strategies for reducing CHD risk by augmenting this activity. Currently available drugs that act to increase HDL-cholesterol concentrations include the statins, fibrates, and niacin. However, although studies such as the Collaborative Atorvastatin Study Group, the ARBITER-2 study, the Helsinki Heart Study, and the VA-HIT provide circumstantial evidence that therapeutic intervention results in the elevation of HDL-cholesterol which translates into beneficial outcomes such as reduced CVD risk, this is not definitive.

Studies have suggested an association between high HDL-cholesterol levels and the epidemiology of breast and lung cancer risk. High HDL-cholesterol is associated with low risk of developing NHL in a dose-responsive manner. Further studies on the potential role of HDL-cholesterol as an early indicator or even as an etiologic factor of these cancers will be of substantial importance to public health considering the high prevalence of low HDL-cholesterol in developed and developing countries.

Low HDL-cholesterol is common in adults and contributes to high rates of cardiovascular disease and may be linked to subsequent neurodegenerative and neurovascular diseases. Numerous epidemiological studies have shown a protective association between HDL-cholesterol and cognitive impairment and dementia. There are a number of studies that have shown an association between low levels of HDLcholesterol and the risk of AD and VD. Therefore, the modulation of HDL function and its concentrations in serum will significantly impact future approaches to the management of cardiovascular diseases, cancers, and neurodegenerative and neurovascular diseases such as AD and VD in both the primary and secondary prevention settings.

\section{Conflict of Interests}

The authors have no conflict of interests to report.

\section{References}

[1] P. Barter, J. Kastelein, A. Nunn et al., "High density lipoproteins (HDLs) and atherosclerosis; the unanswered questions," Atherosclerosis, vol. 168, no. 2, pp. 195-211, 2003.

[2] P. K. Shah, S. Kaul, J. Nilsson, and B. Cercek, "Exploiting the vascular protective effects of high-density lipoprotein and its apolipoproteins: an idea whose time for testing is coming, part I," Circulation, vol. 104, no. 19, pp. 2376-2383, 2001.

[3] J. J. Albers, J. H. Tollefson, C. H. Chen, and A. Steinmetz, "Isolation and characterization of human plasma lipid transfer proteins," Arteriosclerosis, vol. 4, no. 1, pp. 49-58, 1984.

[4] E. R. Skinner, "High-density lipoprotein subclasses," Current Opinion in Lipidology, vol. 5, no. 3, pp. 241-247, 1994.

[5] A. M. Gotto, "Low high-density lipoprotein cholesterol as a risk factor in coronary heart disease: a working group report," Circulation, vol. 103, no. 17, pp. 2213-2218, 2001.

[6] H. Drexel, "Reducing risk by raising HDL-cholesterol: the evidence," European Heart Journal, Supplement, vol. 8, pp. F23-F29, 2006.

[7] P. P. Toth, "High-density lipoprotein as a therapeutic target: clinical evidence and treatment strategies," American Journal of Cardiology, vol. 96, no. 9, pp. 50K-58K, 2005.

[8] D. J. Gordon, J. L. Probstfield, R. J. Garrison et al., "Highdensity lipoprotein cholesterol and cardiovascular disease. Four prospective American studies," Circulation, vol. 79, no. 1, pp. 8-15, 1989.

[9] W. P. Castelli, "Cholesterol and lipids in the risk of coronary artery disease. The Framingham Heart Study," Canadian Journal of Cardiology, vol. 4, supplement A, pp. 5-10, 1988.

[10] U. Goldbourt, S. Yaari, and J. H. Medalie, "Isolated low HDL cholesterol as a risk factor for coronary heart disease mortality: a 21-year follow-up of 8000 men," Arteriosclerosis, Thrombosis, and Vascular Biology, vol. 17, no. 1, pp. 107-113, 1997.

[11] M. J. Stampfer, F. M. Sacks, S. Salvini, W. C. Willett, and C. H. Hennekens, "A prospective study of cholesterol, apolipoproteins, and the risk of myocardial infarction," The New England Journal of Medicine, vol. 325, no. 6, pp. 373-381, 1991.

[12] G. Assmann, P. Cullen, and H. Schulte, "The Münster Heart Study (PROCAM). Results of follow-up at 8 years," European Heart Journal, vol. 19, pp. A2-A11, 1998.

[13] W. B. Kannel, "Range of serum cholesterol values in the population developing coronary artery disease," American Journal of Cardiology, vol. 76, no. 9, pp. 69C-77C, 1995.

[14] D. M. Capuzzi, J. R. Guyton, J. M. Morgan et al., "Efficacy and safety of an extended-release niacin (Niaspan): a longterm study," American Journal of Cardiology, vol. 82, no. 12, pp. 74U-81U, 1998.

[15] J. R. Guyton, A. C. Goldberg, R. A. Kreisberg, D. L. Sprecher, H. R. Superko, and C. M. O'Connor, "Effectiveness of once-nightly dosing of extended-release niacin alone and in combination for hypercholesterolemia," American Journal of Cardiology, vol. 82, no. 6, pp. 737-743, 1998.

[16] J. M. McKenney, L. S. McCormick, S. Weiss, M. Koren, S. Kafonek, and D. M. Black, "A randomized trial of the effects of atorvastatin and niacin in patients with combined hyperlipidemia or isolated hypertriglyceridemia," American Journal of Medicine, vol. 104, no. 2, pp. 137-143, 1998. 
[17] W. P. Castelli, R. J. Garrison, P. W. F. Wilson et al., "Incidence of coronary heart disease and lipoprotein cholesterol levels. The Framingham Study," Journal of the American Medical Association, vol. 256, no. 20, pp. 2835-2838, 1986.

[18] A. J. Taylor, H. J. Lee, and L. E. Sullenberger, "The effect of 24 months of combination statin and extended-release niacin on carotid intima-media thickness: ARBITER 3," Current Medical Research and Opinion, vol. 22, no. 11, pp. 2243-2250, 2006.

[19] H. B. Rubins, S. J. Robins, D. Collins et al., "Gemfibrozil for the secondary prevention of coronary heart disease in men with low levels of high-density lipoprotein cholesterol," New England Journal of Medicine, vol. 341, no. 6, pp. 410-418, 1999.

[20] M. H. Frick, O. Elo, and K. Haapa, "Helsinki Heart Study: primary-prevention trial with gemfibrozil in middle-aged men with dyslipidemia. Safety of treatment, changes in risk factors, and incidence of coronary heart disease," New England Journal of Medicine, vol. 317, no. 20, pp. 1237-1245, 1987.

[21] J. P. Després, I. Lemieux, and S. J. Robins, "Role of fibric acid derivatives in the management of risk factors for coronary heart disease," Drugs, vol. 64, no. 19, pp. 2177-2198, 2004.

[22] A. Császár, "Hypertriglyceridemia, the coronary heart disease risk marker "solved"'" Acta Physiologica Hungarica, vol. 92, no. 2, pp. 109-120, 2005.

[23] T. Meade, R. Zuhrie, C. Cook, and J. Cooper, "Bezafibrate in men with lower extremity arterial disease: randomised controlled trial," British Medical Journal, vol. 325, no. 7373, pp. 1139-1141, 2002.

[24] A. Keech, R. J. Simes, P. Barter et al., "Effects of longterm fenofibrate therapy on cardiovascular events in 9795 people with type 2 diabetes mellitus (the FIELD study): randomised controlled trial," The Lancet, vol. 366, no. 9500, pp. 1849-1861, 2005.

[25] G. F. Lewis and D. J. Rader, "New insights into the regulation of HDL metabolism and reverse cholesterol transport," Circulation Research, vol. 96, no. 12, pp. 1221-1232, 2005.

[26] J. G. Robinson and M. H. Davidson, "Investigational drugs targeting HDL-C metabolism and reverse cholesterol transport," Future Lipidology, vol. 2, no. 3, pp. 285-301, 2007.

[27] M. J. Chapman, G. Assmann, J. C. Fruchart, J. Shepherd, and C. Sirtori, "Raising high-density lipoprotein cholesterol with reduction of cardiovascular risk: the role of nicotinic acid-a position paper developed by the European Consensus Panel on HDL-C," Current Medical Research and Opinion, vol. 20, no. 8, pp. 1253-1268, 2004.

[28] A. D. Watson, J. A. Berliner, S. Y. Hama et al., "Protective effect of high density lipoprotein associated paraoxonase. Inhibition of the biological activity of minimally oxidized low density lipoprotein," Journal of Clinical Investigation, vol. 96, no. 6, pp. 2882-2891, 1995.

[29] B. Mackness, P. Durrington, P. McElduff et al., "Low paraoxonase activity predicts coronary events in the Caerphilly Prospective Study," Circulation, vol. 107, no. 22, pp. 2775-2779, 2003.

[30] C. C. Hedrick, S. R. Thorpe, M. X. Fu et al., "Glycation impairs high-density lipoprotein function," Diabetologia, vol. 43, no. 3, pp. 312-320, 2000.

[31] C. A. Abbott, M. I. Mackness, S. Kumar, A. J. Boulton, and P. N. Durrington, "Serum paraoxonase activity, concentration, and phenotype distribution in diabetes mellitus and its relationship to serum lipids and lipoproteins," Arteriosclerosis, Thrombosis, and Vascular Biology, vol. 15, no. 11, pp. 1812-1818, 1995.

[32] J. R. Nofer, B. Kehrel, M. Fobker, B. Levkau, G. Assmann, and A. V. Eckardstein, "HDL and arteriosclerosis: beyond reverse cholesterol transport," Atherosclerosis, vol. 161, no. 1, pp. 1-16, 2002.

[33] N. N. Chan, H. M. Colhoun, and P. Vallance, "Cardiovascular risk factors as determinants of endothelium-dependent and endothelium-independent vascular reactivity in the general population," Journal of the American College of Cardiology, vol. 38, no. 7, pp. 1814-1820, 2001.

[34] G. Lupattelli, S. Marchesi, A. R. Roscini et al., "Direct association between high-density lipoprotein cholesterol and endothelial function in hyperlipemia," American Journal of Cardiology, vol. 90, no. 6, pp. 648-650, 2002.

[35] S. F. O’Brien, G. F. Watts, D. A. Playford, V. Burke, D. N. O’Neal, and J. D. Best, "Low-density lipoprotein size, highdensity lipoprotein concentration, and endothelial dysfunction in non-insulindependent diabetes," Diabetic Medicine, vol. 14, no. 11, pp. 974-978, 1997.

[36] X. Y. Zhang, S. P. Zhao, X. P. Li, M. Gao, and QI. C. Zhou, "Endothelium-dependent and -independent functions are impaired in patients with coronary heart disease," Atherosclerosis, vol. 149, no. 1, pp. 19-24, 2000.

[37] M. G. Conlan, A. R. Folsom, A. Finch et al., "Associations of factor VIII and von Willebrand factor with age, race, sex, and risk factors for atherosclerosis: the Atherosclerosis Risk in Communities (ARIC) Study," Thrombosis and Haemostasis, vol. 70, no. 3, pp. 380-385, 1993.

[38] N. F. Boyd and V. McGuire, "Evidence of association between plasma high-density lipoprotein cholesterol and risk factors for breast cancer," Journal of the National Cancer Institute, vol. 82, no. 6, pp. 460-468, 1990.

[39] D. Gospodarowicz, G. M. Lui, and R. Gonzalez, "Highdensity lipoproteins and the proliferation of human tumor cells maintained on extracellular matrix-coated dishes and exposed to defined medium," Cancer Research, vol. 42, no. 9, pp. 3704-3713, 1982.

[40] M. Rotheneder and G. M. Kostner, "Effects of low- and high-density lipoproteins on the proliferation of human breast cancer cells in vitro: differences between hormonedependent and hormone-independent cell lines," International Journal of Cancer, vol. 43, no. 5, pp. 875-879, 1989.

[41] J. R. Nofer, R. Junker, E. Pulawski et al., "High density lipoproteins induce cell cycle entry in vascular smooth muscle cells via mitogen activated protein kinase-dependent pathway," Thrombosis and Haemostasis, vol. 85, no. 4, pp. 730-735, 2001.

[42] J. R. Nofer, B. Levkau, I. Wolinska et al., "Suppression of endothelial cell apoptosis by high density lipoproteins (HDL) and HDL-associated lysosphingolipids," Journal of Biological Chemistry, vol. 276, no. 37, pp. 34480-34485, 2001.

[43] M. L. Knapp, S. Al-Sheibani, and P. G. Riches, "Alterations of serum lipids in breast cancer: effects of disease activity, treatment, and hormonal factors," Clinical Chemistry, vol. 37, no. 12, pp. 2093-2101, 1991.

[44] A. P. Hoyer and G. Engholm, "Serum lipids and breast cancer risk: a cohort study of 5,207 Danish women," Cancer Causes and Control, vol. 3, no. 5, pp. 403-408, 1992.

[45] M. Gaard, S. Tretli, and F. Urdal, "Risk of breast cancer in relation to blood lipids: a prospective study of 31,209 Norwegian women," Cancer Causes and Control, vol. 5, no. 6, pp. 501-509, 1994. 
[46] I. A. Bani, C. M. Williams, P. S. Boulter, and J. W. T. Dickerson, "Plasma lipids and prolactin in patients with breast cancer," British Journal of Cancer, vol. 54, no. 3, pp. 439-446, 1986.

[47] E. Kokoglu, I. Karaarslan, H. M. Karaarslan, and H. Baloglu, "Alterations of serum lipids and lipoproteins in breast cancer," Cancer Letters, vol. 82, no. 2, pp. 175-178, 1994.

[48] L. E. Schreier, G. A. Berg, F. M. Basilio, G. I. Lopez, A. E. Etkin, and R. L. Wikinski, "Lipoprotein alterations, abdominal fat distribution and breast cancer," Biochemistry and Molecular Biology International, vol. 47, no. 4, pp. 681-690, 1999.

[49] G. Ray and S. A. Husain, "Role of lipids, lipoproteins and vitamins in women with breast cancer," Clinical Biochemistry, vol. 34, no. 1, pp. 71-76, 2001.

[50] A. S. Furberg, M. B. Veierød, T. Wilsgaard, L. Berstein, and I. Thune, "Serum high density lipoprotein cholesterol, metabolic profile, and breast cancer risk," Journal of the National Cancer Institute, vol. 96, no. 15, pp. 1152-1160, 2004.

[51] P. G. Moorman, B. S. Hulka, R. A. Hiatt et al., "Association between high-density lipoprotein cholesterol and breast cancer varies by menopausal status," Cancer Epidemiology Biomarkers and Prevention, vol. 7, no. 6, pp. 483-488, 1998.

[52] K. Siemianowicz, J. Gminski, M. Stajszczyk et al., "Serum HDL cholesterol concentration in patients with squamous cell and small cell lung cancer," International Journal of Molecular Medicine, vol. 6, no. 3, pp. 307-311, 2000.

[53] S. Umeki, "Decreases in serum cholesterol levels in advanced lung cancer," Respiration, vol. 60, no. 3, pp. 178-181, 1993.

[54] S. Dessi, B. Batetta, D. Pulisci et al., "Altered pattern of lipid metabolism in patients with lung cancer," Oncology, vol. 49, no. 6, pp. 436-441, 1992.

[55] A. M. Fiorenza, A. Branchi, and D. Sommariva, "Serum lipoprotein profile in patients with cancer. A comparison with non-cancer subjects," International Journal of Clinical and Laboratory Research, vol. 30, no. 3, pp. 141-145, 2000.

[56] A. M. Kucharska-Newton, W. D. Rosamond, J. C. Schroeder, A. M. McNeill, J. Coresh, and A. R. Folsom, "HDLcholesterol and the incidence of lung cancer in the Atherosclerosis Risk in Communities (ARIC) study," Lung Cancer, vol. 61, no. 3, pp. 292-300, 2008.

[57] J. Ahn, U. Lim, S. J. Weinstein et al., "Prediagnostic total and high-density lipoprotein cholesterol and risk of cancer," Cancer Epidemiology Biomarkers and Prevention, vol. 18, no. 11, pp. 2814-2821, 2009.

[58] A. R. Tall, "An overview of reverse cholesterol transport," European Heart Journal, vol. 19, pp. A31-A35, 1998.

[59] A. Von Eckardstein, M. Hersberger, and L. Rohrer, "Current understanding of the metabolism and biological actions of HDL," Current Opinion in Clinical Nutrition and Metabolic Care, vol. 8, no. 2, pp. 147-152, 2005.

[60] E. Esteve, W. Ricart, and J. M. Fernández-Real, "Dyslipidemia and inflammation: an evolutionary conserved mechanism," Clinical Nutrition, vol. 24, no. 1, pp. 16-31, 2005.

[61] E. A. Engels, "Inflammation in the development of lung cancer: epidemiological evidence," Expert Review of Anticancer Therapy, vol. 8, no. 4, pp. 605-615, 2008.

[62] R. J. Spiegel, E. J. Schaefer, I. T. Magrath, and B. K. Edwards, "Plasma lipid alterations in leukemia and lymphoma," American Journal of Medicine, vol. 72, no. 5, pp. 775-782, 1982.
[63] J. D. Blackman, V. G. Cabana, and T. Mazzone, "The acutephase response and associated lipoprotein abnormalities accompanying lymphoma," Journal of Internal Medicine, vol. 233, no. 2, pp. 201-204, 1993.

[64] U. Lim, T. Gayles, H. A. Katki et al., "Serum high-density lipoprotein cholesterol and risk of non-hodgkin lymphoma," Cancer Research, vol. 67, no. 11, pp. 5569-5574, 2007.

[65] M. Navab, G. M. Ananthramaiah, S. T. Reddy et al., "The double jeopardy of HDL," Annals of Medicine, vol. 37, no. 3, pp. 173-178, 2005.

[66] U. J. F. Tietge, C. Maugeais, W. Cain, and D. J. Rader, "Acute inflammation increases selective uptake of HDL cholesteryl esters into adrenals of mice overexpressing human sPLA," American Journal of Physiology, vol. 285, no. 2, pp. E403-E411, 2003.

[67] L. E. Spieker, F. Ruschitzka, T. F. Lüscher, and G. Noll, "HDL and inflammation in atherosclerosis," Current Drug Targets Immune, Endocrine and Metabolic Disorders, vol. 4, no. 1, pp. 51-57, 2004.

[68] G. W. Cockerill, T. Y. Huehns, A. Weerasinghe et al., "Elevation of plasma high-density lipoprotein concentration reduces interleukin-1-induced expression of E-selectin in an in vivo model of acute inflammation," Circulation, vol. 103, no. 1, pp. 108-112, 2001.

[69] B. J. Ansell, K. E. Watson, A. M. Fogelman, M. Navab, and G. C. Fonarow, "High-density lipoprotein function: recent advances," Journal of the American College of Cardiology, vol. 46, no. 10, pp. 1792-1798, 2005.

[70] P. J. Whitehouse, C. G. Sciulli, and R. M. Mason, "Dementia drug development: use of information systems to harmonize global drug development," Psychopharmacology Bulletin, vol. 33, no. 1, pp. 129-133, 1997.

[71] I. J. Martins, E. Hone, J. K. Foster et al., "Apolipoprotein E, cholesterol metabolism, diabetes, and the convergence of risk factors for Alzheimer's disease and cardiovascular disease," Molecular Psychiatry, vol. 11, no. 8, pp. 721-736, 2006.

[72] J. H. Xuereb, C. Brayne, C. Dufouil et al., "Neuropathological findings in the very old. Results from the first 101 brains of a population-based longitudinal study of dementing disorders," Annals of the New York Academy of Sciences, vol. 903, pp. 490-496, 2000.

[73] G. P. Eckert, C. Kirsch, S. Leutz, W. G. Wood, and W. E. Müller, "Cholesterol modulates amyloid beta-peptide's membrane interactions," European Archives of Psychiatry and Clinical Neuroscience, vol. 252, no. 2, pp. 63-67, 2003.

[74] A. R. Koudinov and N. V. Koudinova, "Essential role for cholesterol in synaptic plasticity and neuronal degeneration," The FASEB Journal, vol. 15, no. 10, pp. 1858-1860, 2001.

[75] M. Guglielmotto, L. Giliberto, E. Tamagno, and M. Tabaton, "Oxidative stress mediates the pathogenic effect of different Alzheimer's disease risk factors," Front Aging Neuroscience, vol. 9, no. 2, p. 3, 2010.

[76] M. Dominique Ashen and R. S. Blumenthal, "Low HDL cholesterol levels," New England Journal of Medicine, vol. 353, no. 12, pp. 1252-1260, 2005.

[77] M. A. Ward, C. M. Carlsson, M. A. Trivedi, M. A. Sager, and S. C. Johnson, "The effect of body mass index on global brain volume in middle-aged adults: a cross sectional study," BMC Neurology, vol. 5, Article ID 23, 2005.

[78] A. F. Kramer, K. I. Erickson, and S. J. Colcombe, "Exercise, cognition, and the aging brain," Journal of Applied Physiology, vol. 101, no. 4, pp. 1237-1242, 2006. 
[79] N. Barzilai, G. Atzmon, C. A. Derby, J. M. Bauman, and R. B. Lipton, "A genotype of exceptional longevity is associated with preservation of cognitive function," Neurology, vol. 67, no. 12, pp. 2170-2175, 2006.

[80] A. Singh-Manoux, D. Gimeno, M. Kivimaki, E. Brunner, and M. G. Marmot, "Low HDL cholesterol is a risk factor for deficit and decline in memory in midlife the whitehall II study," Arteriosclerosis, Thrombosis, and Vascular Biology, vol. 28, no. 8, pp. 1556-1562, 2008.

[81] S. E. Wahrle, H. Jiang, M. Parsadanian et al., "Overexpression of ABCA1 reduces amyloid deposition in the PDAPP mouse model of Alzheimer disease," Journal of Clinical Investigation, vol. 118, no. 2, pp. 671-682, 2008.

[82] O. F. Olesen and L. Dagø, "High density lipoprotein inhibits assembly of amyloid $\beta$-peptides into fibrils," Biochemical and Biophysical Research Communications, vol. 270, no. 1, pp. 62-66, 2000.

[83] S. Lesné, T. K. Ming, L. Kotilinek et al., "A specific amyloid- $\beta$ protein assembly in the brain impairs memory," Nature, vol. 440, no. 7082, pp. 352-357, 2006.

[84] J. Hardy and K. Cullen, "Amyloid at the blood vessel wall," Nature Medicine, vol. 12, no. 7, pp. 756-757, 2006.

[85] A. Kontush, "Amyloid- $\beta$ : an antioxidant that becomes a pro-oxidant and critically contributes to Alzheimer's disease," Free Radical Biology and Medicine, vol. 31, no. 9, pp. 1120-1131, 2001.

[86] A. B. Reiss, K. A. Siller, M. M. Rahman, E. S. L. Chan, J. Ghiso, and M. J. De Leon, "Cholesterol in neurologic disorders of the elderly: stroke and Alzheimer's disease," Neurobiology of Aging, vol. 25, no. 8, pp. 977-989, 2004.

[87] M. Michikawa, "Cholesterol paradox: is high total or low HDL cholesterol level a risk for Alzheimer's disease?” Journal of Neuroscience Research, vol. 72, no. 2, pp. 141-146, 2003.

[88] H. Wolf, A. Hensel, T. Arendt, M. Kivipelto, B. Winblad, and H. J. Gertz, "Serum lipids and hippocampal volume: the link to Alzheimer's disease?" Annals of Neurology, vol. 56, no. 5, pp. 745-748, 2004.

[89] M. Kivipelto, T. Ngandu, T. Laatikainen, B. Winblad, H. Soininen, and J. Tuomilehto, "Risk score for the prediction of dementia risk in 20 years among middle aged people: a longitudinal, population-based study," Lancet Neurology, vol. 5, no. 9, pp. 735-741, 2006.

[90] G. Zuliani, A. Ble, R. Zanca et al., "Lipoprotein profile in older patients with vascular dementia and Alzheimer's disease," BMC Geriatrics, vol. 1, pp. 1-5, 2001.

[91] M. Kuriyama, K. Takahashi, T. Yamano et al., "Low levels of serum apolipoprotein A I and A II in senile dementia," Japanese Journal of Psychiatry and Neurology, vol. 48, no. 3, pp. 589-593, 1994.

[92] T. J. Muckle and J. R. Roy, "High-density lipoprotein cholesterol in differential diagnosis of senile dementia," The Lancet, vol. 1, no. 8439, pp. 1191-1193, 1985.

[93] E. Van Exel, A. J. M. De Craen, J. Gussekloo et al., "Association between high-density lipoprotein and cognitive impairment in the oldest old," Annals of Neurology, vol. 51, no. 6, pp. 716-721, 2002.

[94] R. L. Sacco, R. T. Benson, D. E. Kargman et al., "High-density lipoprotein cholesterol and ischemic stroke in the elderly the northern manhattan stroke study," Journal of the American Medical Association, vol. 285, no. 21, pp. 2729-2735, 2001.

[95] S. N. Romas, M. X. Tang, L. Berglund, and R. Mayeux, "APOE genotype, plasma lipids, lipoproteins, and $\mathrm{AD}$ in community elderly," Neurology, vol. 53, no. 3, pp. 517-521, 1999.
[96] C. Reitz, M. X. Tang, J. Luchsinger, and R. Mayeux, "Relation of plasma lipids to Alzheimer disease and vascular dementia," Archives of Neurology, vol. 61, no. 5, pp. 705-714, 2004.

[97] G. Li, J. B. Shofer, W. A. Kukull et al., "Serum cholesterol and risk of Alzheimer disease: a community-based cohort study," Neurology, vol. 65, no. 7, pp. 1045-1050, 2005.

[98] R. D. Abbott, D. S. Sharp, C. M. Burchfiel et al., "Crosssectional and longitudinal changes in total and high-densitylipoprotein cholesterol levels over a 20 -year period in elderly men: the Honolulu Heart Program," Annals of Epidemiology, vol. 7, no. 6, pp. 417-424, 1997.

[99] A. Ferrara, E. Barrett-Connor, and J. Shan, "Total, LDL, and HDL cholesterol decrease with age in older men and women: the Rancho Bernardo Study 1984-1994," Circulation, vol. 96, no. 1, pp. 37-43, 1997.

[100] M. Kawano, M. Kawakami, M. Otsuka, H. Yashima, T. Yaginuma, and A. Ueki, "Marked decrease of plasma apolipoprotein AI and AII in Japanese patients with lateonset non-familial Alzheimer's disease," Clinica Chimica Acta, vol. 239, no. 2, pp. 209-211, 1995.

[101] A. Merched, Y. Xia, S. Visvikis, J. M. Serot, and G. Siest, "Decreased high-density lipoprotein cholesterol and serum apolipoprotein AI concentrations are highly correlated with the severity of Alzheimer's disease," Neurobiology of Aging, vol. 21, no. 1, pp. 27-30, 2000.

[102] J. S. Saczynski, L. White, R. L. Peila, B. L. Rodriguez, and L. J. Launer, "The relation between apolipoprotein A-I and dementia: the honolulu-asia aging study," American Journal of Epidemiology, vol. 165, no. 9, pp. 985-992, 2007. 


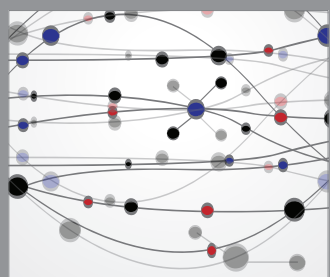

The Scientific World Journal
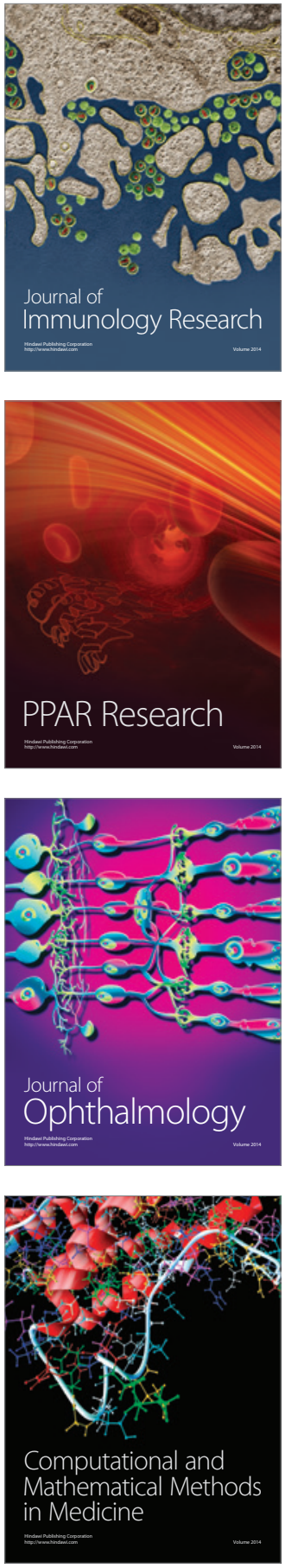

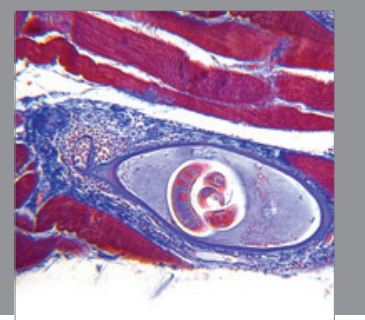

Gastroenterology

Research and Practice
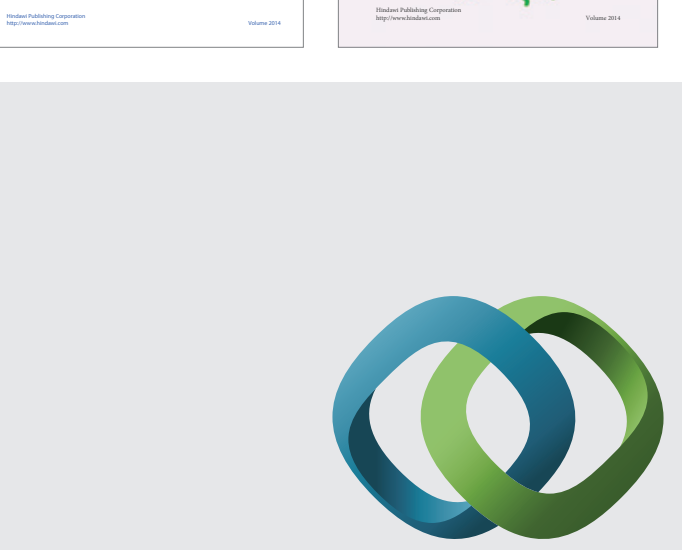

\section{Hindawi}

Submit your manuscripts at

http://www.hindawi.com
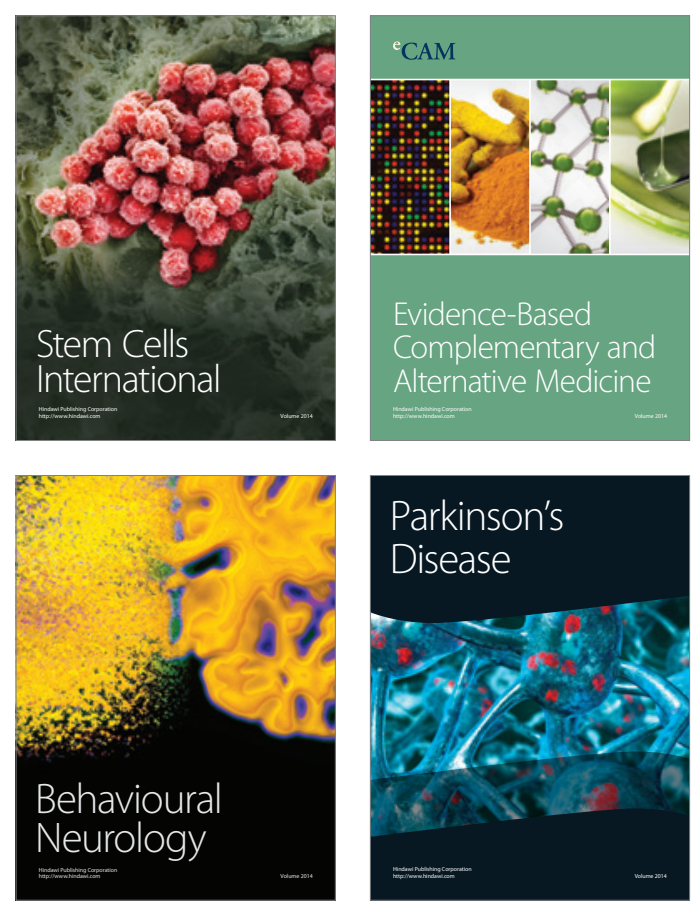

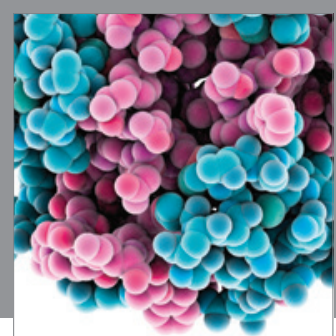

Journal of
Diabetes Research

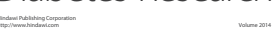

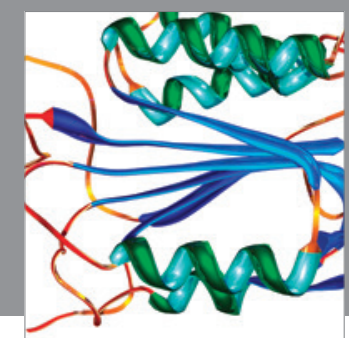

Disease Markers
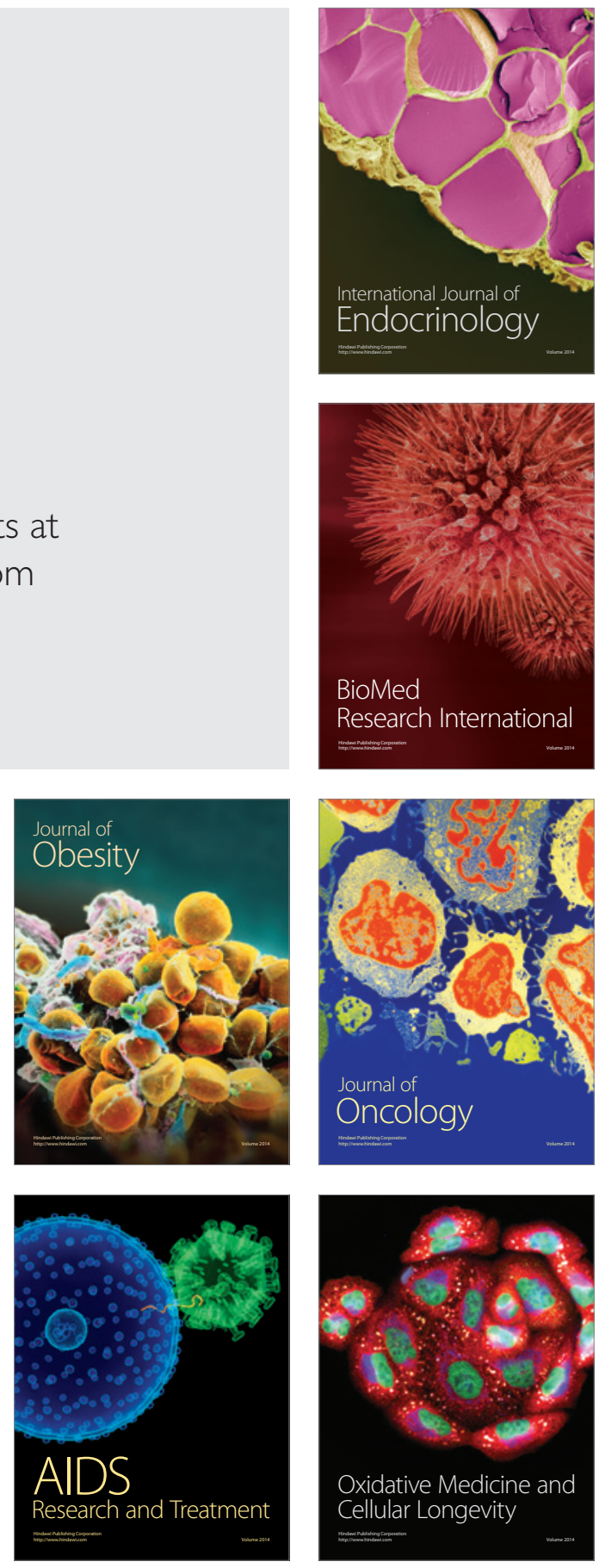